\title{
Effect of Dates (Phoenix Dactilyfera L) on Male Infertility
}

\author{
Semalina Wahyudi ${ }^{1}$, R.A. Retno Ekowati ${ }^{2}$, Andi Rinaldi ${ }^{3}$ \\ ${ }^{1}$ Faculty of Medicine, Universitas Padjadjaran, ${ }^{2}$ Departmen of Biology Cell, Faculty of Medicine, \\ Universitas Padjadjaran, ${ }^{3}$ Department of Obstetrics and Gynecology, Faculty of Medicine, \\ Universitas Padjadjaran/Dr. Hasan Sadikin General Hospital, Bandung
}

\begin{abstract}
Background: Infertility can be caused by prolonged use of paracetamol that leads to a decrease in the sperm concentration, motility, and morphology. Dates (Phoenix Dactilyfera L) have natural antioxidant effects through several mechanisms, such as neutralizing free radicals, against $\mathrm{NO}, \mathrm{OH}$, and $\mathrm{H} 2 \mathrm{O} 2$, and also preventing lipid peroxidation. This study aimed to investigate the effect of dates on sperm concentration, motility, and morphology.

Methods: An experimental study was conducted in the Laboratory of Cell Biology Department, Faculty of Medicine, Universitas Padjadjaran, during October-November 2012. Twenty two infertile male wistar rats were divided randomly into 2 groups. Group A was given $72 \mathrm{mg}$ paracetamol/rat/day orally and group B was given $72 \mathrm{mg}$ paracetamol/rat/day orally and $80 \%$ dates infusion/rat/day orally for 28 days and on the 29th day, sperm concentration, motility, and morphology were measured. Results were analyzed using unpaired t-testor Mann Whitney test.

Result: In the control group, 502.73(100.66) sperm concentrations were compared to 397.55(143.07) in the treatment group. However, the sperm concentration mean in the treatment group was not significantly decreased $(p>0.05)$ compared to the control group. The percentage of progressive sperm motility in the treatment group increased significantly compared to the control group. Meanwhile, the percentage of nonprogressive immotal sperm morphology was not significantly decreased. The percentage of normal sperm in the treatment group increased significantly $(\mathrm{p}<0.05)$ than the control group, while the percentage of abnormal sperm in the treatment group decreased significantly $(\mathrm{p}<0.05)$ compared to the control group. Conclusion: The dates affect sperm motility and morphology of infertile rats.
\end{abstract}

Keywords: Dates, infertility, paracetamol, sperm

\section{Introduction}

Infertility is the inability of a couple to have children after two years of regular intercourse without using a contraception. ${ }^{1}$ Many causes of the infertility, one of which is contributed by male as much as $30-40 \%$ cases. $^{2}$ One of the mechanism of infertility is caused by a male is the cell damage caused by the reactive oxygen species (ROS). The extent of damage is caused by ROS depends on the balance between oxidative stress and the defense system. ${ }^{3}$ According to Agarwal et al. ${ }^{4}$ one of the causes of oxidative stress are drugs such as aspirin and paracetamol (acetaminophen) can increase the production oxidative stress by increasing activity of cytochrome P450, which will increase the formation ROS. To overcome the problem of infertility caused by oxidative stress reactions that will generate reactive oxygen species (ROS), also known as free radicals, should be given an antioxidant that can counteract free radicals. Beside naturally contained in the body, antioxidants can be found from the food intake, in the form of nutrients and nonnutrients or phytochemicals contained in the fruits and vegetables. ${ }^{5}$ This study is conducted to counteract the oxidative stress caused by prolonged use of paracetamol by using date palm fruits that has high potential antioxidant activity to determine an effect on number, motility, and morphology of sperm in infertile adult male rat caused by longterm use of paracetamol.

Correspondence: Semalina Wahyudi, Faculty of Medicine, Universitas Padjadjaran, Jalan Raya Bandung-Sumedang Km.21, Jatinangor, Sumedang, Indonesia, Phone: +6285295252263 Email: semalinawahyudi@yahoo.com 


\section{Methods}

An experimental study was conducted to 22 male wistar rats 3 months with average weight 300 grams which has no anatomical abnormalities. The rats were randomized selected into 2 groups, group $A$, the control was given only $72 \mathrm{mg} / 3 \mathrm{ml} /$ day paracetamol orally for 28 days and group $\mathrm{B}$ was given $80 \%$ of date palm fruits infusion orally as much as $3 \mathrm{ml} /$ day, then given $72 \mathrm{mg} / 3 \mathrm{ml} /$ day paracetamol orally for 28 days. On the 29 th, all rats were dissected to retrieve the ductus epididymis. (The date palm fruits used are Ajwa Dates/"Prophet dates"). This experiment was conducted in accordance with the principles of the 3Rs, which are replacement, reduction and refinement. ${ }^{6}$

Ductus epididymis taken was dissolved and made homogeneous using a solution of phosphate buffered saline (PBS). Assessment of sperm concentration per mm3 was carried out by dripping sperm solution into an Improved Neubauer Haemocytometer and then covered with a cover glass and counted only if the sperm has a complete head and a tail. Assessment of the sperm motility was made by the dripping solution on the object glass and covered with a cover glass, to observe the movement by its category; progressive motility, non progressive motility and immotile. Assessment of the sperm morphology performed with fixation using $40 \%$ methanol for five minutes, rinse and then drop with $5 \%$ safranin for five minutes, then dip in a buffer solution, and then performed staining using crystal violet. ${ }^{7}$ Normality of the data was tested using SapiroWilk test, and the data was analyzed using a parametric unpaired t-test, or Mann Whitneytest.

\section{Result}

In the control group, there was 502.73 sperm concentration compared to treatment group (397.55). While immotal sperms in group A were found more than in group B. Moreover, the percentage of abnormal morphology in sperms of group B was less than in group A (Table 1).

However, the mean of sperm concentration in the treatment group were not significantly decreased $(P>0.05)$ than the control group (Figure 1).

The percentage of progressive sperm motility in the treatment group increased significantly compared to the control group. Meanwhile, the percentage of nonprogressive immotal sperm morphology were not significantly decreased. The percentage of normal sperm in the treatment group increased significantly $(\mathrm{P}<0.05)$ than the control group, meanwhile the percentage of abnormal sperm in the treatment group decreased significantly $(\mathrm{P}<0.05)$ than in the control group(Figure 2$)$.

Table 1 The Sperm Concentration, Motility, and Morphology in Control and Treatment Groups

\begin{tabular}{|c|c|c|c|}
\hline Parameters & & Group & Mean (SD) \\
\hline \multirow[t]{2}{*}{ Sperm concentration (sperm count/mm3) } & & A & $502.73(100.66)$ \\
\hline & & B & $397.55(143.07)$ \\
\hline \multirow[t]{6}{*}{ Sperm motility (\%) } & PR & A & $7.45(4.20)$ \\
\hline & & B & $18.36(7.46)$ \\
\hline & NP & A & $28.82(9.86)$ \\
\hline & & B & $25.45(8.20)$ \\
\hline & IM & A & $63.73(9.85)$ \\
\hline & & B & $56.27(12.93)$ \\
\hline \multirow[t]{4}{*}{ Sperm morphology (\%) } & $\mathrm{N}$ & A & $85.64(4.31)$ \\
\hline & & B & $94.36(4.10)$ \\
\hline & $\mathrm{AB}$ & A & $14.36(4.31)$ \\
\hline & & $\mathrm{B}$ & $4.73(2.28)$ \\
\hline
\end{tabular}

Note; PR (progressive motility), NP (nonprogressive motility), IM (immotile), N (normal), AB (abnormal), A(paracetamol), B (date palm fruits and paracetamol) 


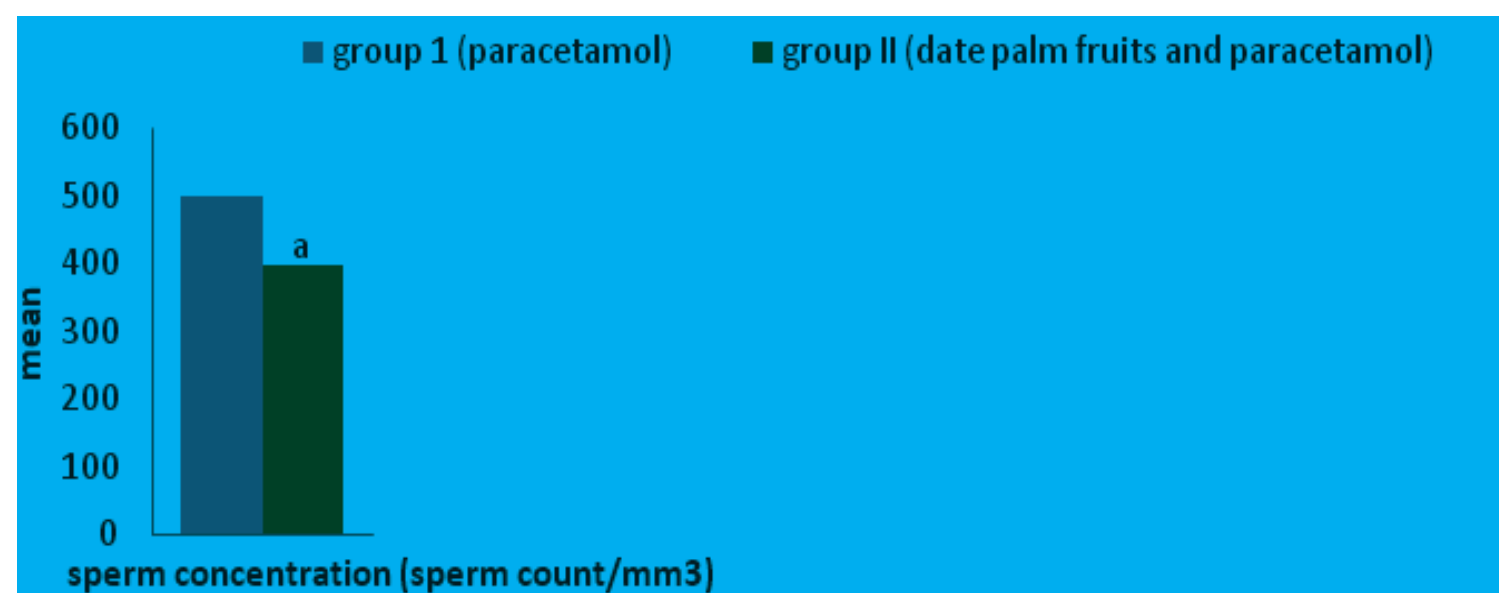

Figure 1 The Effect of Date Palm Fruits on Sperm Concentration.

Note; a (notsignificantly different from control P $>0.05$ )

\section{Discussion}

According to Wafaa et $a l^{8}{ }^{8}$ paracetamol decreases the number and motility of sperm that also triggering the apoptosis of sperm cells, which lowers testicular size indicating the occurrence of mild testicular toxicity. Dates have a natural antioxidant such as provitamin A (beta carotene), vitamin C and other compounds such as flavonoids, minerals, pectin, phenolic, and sterols. ${ }^{9}$ It contains the free radical scavengers such as zinc, manganese, magnesium, selenium, carotenoids, phenolic and vitamin B complex. ${ }^{9}$

Dates are believed to enhance the sexual performance in male, but there is a lack of information about the physiological effects and phytochemicals from dates in humans. ${ }^{10}$ The gonadotropin effect of dates can also increase the size of the testes and seminal vesicles which also shows an increase in plasma levels of estradiol and testosterone which will increase the number of sperm.11Dates can be a source of antioxidants through several mechanisms, such as neutralizing free radicals, against $\mathrm{NO}, \mathrm{OH}$, and $\mathrm{H} 2 \mathrm{O} 2$ and preventing lipid peroxidation.12limiting the formation of free radicals, destroying free radicals or its precursor, and stimulates antioxidant enzymes activity. ${ }^{13}$ Date palm fruits infusion contains the compounds to lessen the anti oxidant effects.

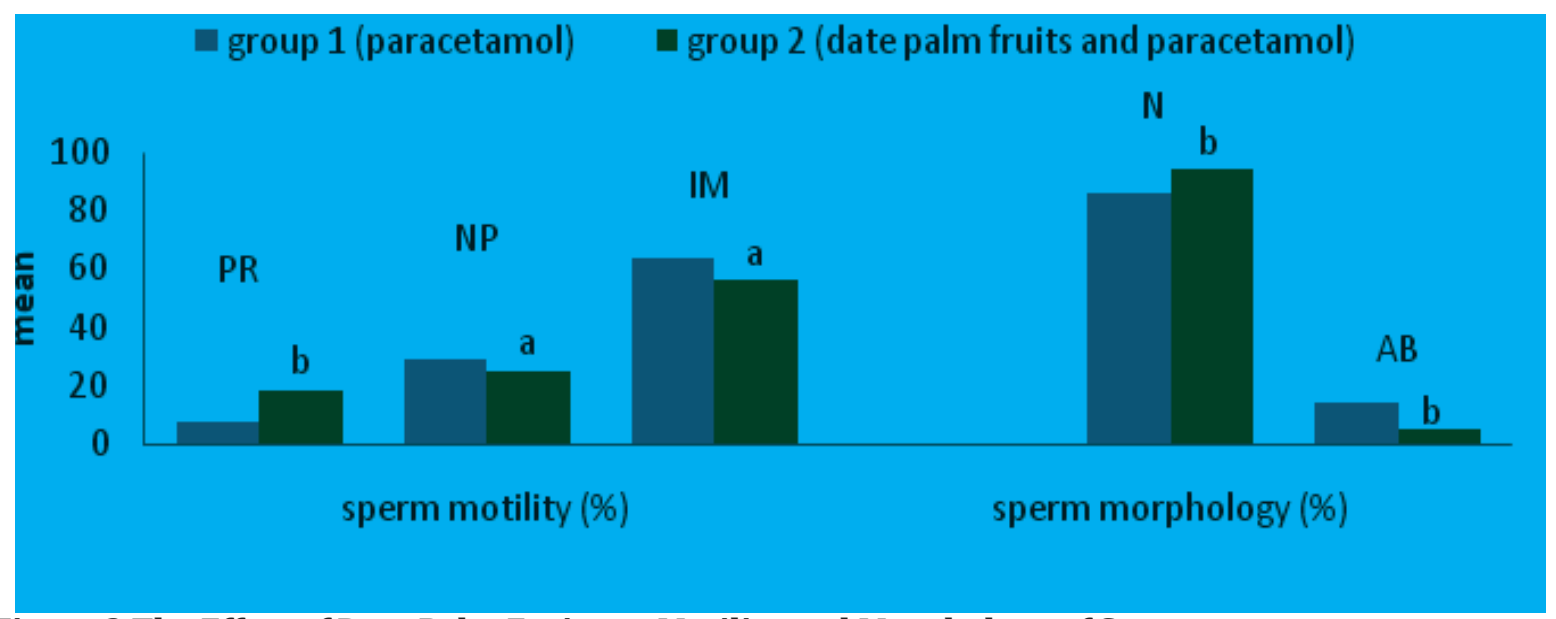

Figure 2 The Effect of Date Palm Fruits on Motility and Morphology of Sperm

Note; PR (progressive motility), NP (nonprogressive motility), IM (immotile), N (normal), AB (abnormal), a (not significantly different from control $\mathrm{P}>0.05$ ), $\mathrm{b}$ (significantly different from control $\mathrm{P}<0.05$ ) 
Paracetamol causes anti motility effects that works directly on spermatozoa by inhibiting the activity of nitric oxide or work indirectly by altering the environment in the epididymis through its action in inhibiting the enzyme cyclooxygenase. Nitric oxide is important in hyper activation of sperm to the acrosome reaction and critical help in the process of fertilization to fertilize an egg. In addition, high doses of paracetamol can cause a lipid peroxidation which can damage the sperm fertilization potential by inhibiting glycolysis and reduced supply of ATP in helping motility of sperm. ${ }^{8}$

Paracetamol may increase the production of oxidative stress by increasing the activity of cytochrome P450 to increase the formation of reactive oxygen species (ROS). Oxidative stress occurs when the production of ROS exceeds the body's natural antioxidant resistance mechanisms which will cause a cellular damage. ROS causes the infertility in two ways. First, it damages the sperm membrane, lower sperm the motility and ability to fuse with the oocyte. Second, ROS can alter the DNA of the sperm, resulting in a defect in DNA. ${ }^{4}$ Dates have an antioxidant effect by increasing glutathione enzyme(GSH), superoxide dismutase (SOD) and catalase (CAT). Dates also have an effect against the testicular dysfunction in the infertile rat by increasing normalization of estradiol and testosterone levels and other sperm parameters. Dates protecting testicular tissue by decreasing abnormal cells and repair damaged DNA. ${ }^{14}$ However, this study indicates that the effect of palm fruit was only on sperm motility and morphology.

This study has no control group consisting of rats that were neither given paracetamol nor paracetamol and palm fruit, so that the data of sperm concentration, motility and morphology in normal rats cannot be obtained.

As conclusion, dates can improve sperm motility and morphology of infertile rat induced by paracetamol, while the sperm concentration remained unchanged.

\section{Reference}

1. WHO. Health topics: infertility.2012 [Cited 2012 February 20]. Available from: http:// www.who.int/topics/infertility/en/

2. Burney RO, Schust DJ, Yao MW. Infertility. In: Berek JS, editor. Berek \& Novak's Gynecology.14 $4^{\text {th }}$ ed.Philadelphia: Lippincot William \& Wilkins; 2006. p. 1185-259.

3. Ford WC. Biological mechanisms of male infertility. The Lancet. 2001;357(9264):1223-4.

4. Tremellen K. Oxidative stress and male infertility-a clinical perspective. Hum Reprod Update. 2008;14(3):243-58.

5. Fayadh JM, AlShowiman SS. Chemical composition of date palm (Phoenix dactylifera L.). Jour Chem Soc Pak. 1990;12(1):95-100.

6. Hubrecht RC, Kirkwood J. The UFAW handbook on the care and management of laboratory and other research animal. $8^{\text {th }}$ ed. Singapore: Wiley-Blackwell; 2010.

7. WHO, Department of Reproductive Health and Research. WHO laboratory manual for the examination and processing of human semen. $5^{\text {th }}$ ed. Switzerland: WHO Library Cataloguing Data; 2010. p. 21-36.

8. Ratnasooriya WD, Jayakody JR. Long term administration of large doses of paracetamol impairs the reproductive competence of male rats. Asian J Androl. 2000;2(4):247-55.

9. Yasmina M, Abdennour C, Loudjani F. Influence of palm date and vitamin C supplementation on testicular functions of domestic rabbit Oryctolagus Cuniculus under mercury exposure. Ann Biol Res. 2011;2(3):359-67.

10. Omar AA, Shanawany MM, Ismail AA, Mohsen MK. The effect of palm pollen grains and date extract on the spermatogenic activity of male guinea pigs. Proceeding of the Second Symposium on Date Palm; 2010 February 2nd; Burydah. Qassim: King Saud University; 2010.

11. Bahmanpour S, Talaei T, Vojdani Z, Panjehshahin MR, Poostpasand A, Zareei $S$, et al. Effect of phoenix dactylifera pollen on sperm parameters and reproductive system of adult male rats. Iran J Med Sci. 2006;31(4):208-12.

12. Al-Mamary M, Al-Habori M, Al-Zubairi, SA. The in vitro antioxidant activity of different types of palm dates (Phoenix dactylifera) syrups. Arabian Journal of Chemistry.[Online Journal]. 2010. [Cited 2012 March 26]. Available from: http:// www.sciencedirect.com.

13. Whitney E, Rolfes SR. Understanding nutrition. $11^{\text {th }}$ ed. Belmont: Thomson Wadsworth; 2008. p. 390-1.

14. Hasan WA, EL-kashlan AM, Ehssan NA. Egyptian date palm pollen ameliorates testicular dysfunction induced by cadmium chloride in adult male rats. Journal of American Science.2012;8(4):659-69. 